\title{
CARDIOVASCULAR COMORBIDITY ON THE RISK OF DYING IN CONFIRMED OF COVID-19 PATIENTS
}

\author{
Syndia Puspitasari \\ Masters Program in Public Health, Universitas Sebelas Maret
}

\begin{abstract}
Background: Pre-existing cardiovascular diseases (CVDs) have been proposed to identify patients at higher risk of adverse coronavirus disease 2019 (COVID-19) outcomes, but existing evidence is conflicting. Estimating the risk of pre-existing comorbidities on coronavirus disease 2019 (COVID-19) mortality may promote the importance of targeting populations at risk to improve survival. This study aimed to explore cardiovascular comorbidity on the risk of dying in confirmed of covid-19 patients.
\end{abstract}

Subjects and Method: This was a systematic review and meta-analysis was conducted by PRISMA flow diagram. The articles were collected from PubMed, Science Direct, and Google Scholar databases. Research problems were formulated in PICO, as follows: (1) Population= patients confirmed COVID-19, (2) Intervention $=$ comorbidity heart disease, (3) Comparison = without comorbidity, and (4) Outcome = death. Keywords used "Heart disease" OR "Cardiovascular disease" OR "Heart failure" OR Hypertension AND "COVID-19 Testing" OR "COVID-19" OR "SARS-CoV-2" AND mortality OR "mortality rate" OR "increase mortality". The inclusion criteria were full text, articles were published from year 2020 to 2021, observational studies, and reported adjusted Odds Ratio. Articles that met the criteria were analyzed by Revman 5.3.

Results: As many as 10 cohort studies from United States New York, Moscow, China, California, Iran, and Italia, reviewed in meta-analysis. This study found that patients confirmed COVID-19 with comorbidity heart disease had higher risk of dying 2.56 times than those without any comorbidity ( $\mathrm{aOR}=2.56 ; 95 \% \mathrm{CI}=1.14$ to $5.74 ; \mathrm{p}=0.002$ ).

Conclusion: Patients confirmed COVID-19 with comorbidity heart disease have higher risk of than those without any comorbidity.

Keywords: cardiovascular disease, comorbidity, death, heart disease COVID-19

\section{Correspondence:}

Syndia Puspitasari. Masters Program in Public Health, Universitas Sebelas Maret. Jl. Ir. Sutami 36A, Surakarta 57126, Central Java. Email: syndiapuss96@gmail.com. Mobile: 082234398706. 